\title{
AN INTELLIGENT CALl ADMisSion CONTROLLER FOR GUARANTEED QOS IN 4G MOBILE NETWORKS
}

\author{
Uduak Umoh $^{1}$, Daniel Asuquo ${ }^{2}$, Imoh Eyoh $^{3}$ and Margaret Offisong ${ }^{4}$ \\ ${ }^{1,2,4}$ Department of Computer Science, University of Uyo, Akwa Ibom State, Nigeria \\ ${ }^{3}$ ASAP Research Group, University of Nottingham Nottingham, United Kingdom
}

\begin{abstract}
Call admission control (CAC), a resource management function, is required to regulate network access to provide the required levels of QoS to emerging services in Fourth Generation (4G) mobile networks. However, CAC is one of the challenging issues for quality of service $(Q o S)$ due to imprecise, uncertain and inaccurate measurements of network data. Although type-1 fuzzy system (T1FLS) can handle the uncertainties related to imprecise data, it cannot adequately handle new problems posed by the complex nature of data traffic and diversity of the QoS requirements of data users. This is because T1FLS is characterised by precise membership functions. This study presents an intelligent CAC controller for $4 G$ network using interval type-2 fuzzy logic (IT2FL) for providing guaranteed QoS requirements. The IT2FLS with fuzzy membership functions can fully cope with uncertainties associated with such dynamic network environments by raising its accuracy for a better performance. The Karnik-Mendel (KM) iterative algorithm and Wu-Mendel (WM) approach are explored for computing the centroid and to derive innerand outer-bound sets for the type-reduced set of IT2FS respectively. The study also implements a T1FLSCAC for comparison with the KM and WM methods. The empirical comparison is made on the designed system with synthetic datasets. Simulation and analyses of results indicate that IT2FLS-CAC using WU approach achieves minimal call blocking probability and provides high performance in CAC decision making with a more reduced root mean square error (RMSE) than IT2FLS-CAC using KM and ITIFLS approaches.
\end{abstract}

\section{KEYWORDS}

Interval type-2 fuzzy logic; Admission control system; 4G Mobile Networks; Computational complexity

\section{INTRODUCTION}

Wireless access has seen exponential growth in past decades and transmission of multimedia applications and services over wireless networks is gaining popularity. This has brought about the emergence of different wireless technologies such as second generation $(2 \mathrm{G})$, third generation $(3 \mathrm{G})$, beyond $3 \mathrm{G}(\mathrm{B} 3 \mathrm{G})$, and $4 \mathrm{G}$ networks to satisfy demands for mobile services and internet access. In $4 \mathrm{G}$ networks, different types of wireless networks are interconnected to support handoff from one technology to another, with the goal of replacing the entire core of cellular networks with a single worldwide cellular network. These wireless systems are designed independently and targeting different service types, data rates, and users, and thus require an intelligent management approach. Effective, secure and efficient operations and resource management are the major challenges facing $4 \mathrm{G}$ Networks. Also, these networks are associated with much uncertainty and imprecision due to escalating number of access points, constant change in propagation channels, random mobility of users, etc. Due to the tremendous growth and complex nature of $4 \mathrm{G}$ networks, it is difficult to manage. In order to control and mange such a complex network, CAC is required [1-5]. 
$\mathrm{CAC}$ is an important resource management function required to regulate network access by restricting access to the network resources to provide the required levels of QoS to emerging services. CAC accepts a new connection request without disrupting the service quality of ongoing connections to ensure fair admission control for efficient service delivery to all categories of call requests. CAC is widely researched in wireless networks as an important tool for QoS provisioning. QoS evaluation is necessary for determining the efficiency of CAC scheme in mobile multimedia networks in terms of signal quality, packet delay, jitter and loss rate, call blocking and dropping probabilities, and transmission rate, etc. The main function of CAC is to decide, at the time of call arrival, whether or not a new call should be admitted into the network or not. A new call is accepted only if QoS constraints are fulfilled without affecting the QoS constraints of the existing calls in the network. Maintaining QoS parameters is necessary for efficient admission control in mobile multimedia networks. Several methods have been used to improve QoS across 4G networks. These methods include Markov models, queuing models, and expert systems, etc. In recent years, type-1 fuzzy logic systems (T1FLS) are widely used to improve the capability of existing CAC methods in mobile networks [6-13].

Type-1 fuzzy set (T1FS) was introduced by Zadeh [11] in 1965 to tackle uncertainty and imprecision, which widely exist in real-life problems.T1FLSs have the ability to process information using linguistic variables and make decision with imprecise, vague, ambiguous, uncertain data. T1FLSs have achieved great success in many different real world applications including wireless sensor networks, Asynchronous Transfer Mode (ATM) networks, wireless cellular networks, and congestion control in 4G Networks [14-21]. However, T1FLS cannot adequately handle the effect of the uncertainties posed by the complex nature of data traffic and by the diversity of the QoS requirements of data users. This is because T1FLS is characterized by precise membership functions. Type-2 fuzzy logic (T2FL), an extension of T1FL, provides additional design degrees of freedom with membership functions that are themselves fuzzy. T2FLS can cope fully in situations where lots of uncertainties are present and have the potential to provide better performance than T1FLS. However, due to computational complexity of using a general T2FLS, IT2FLS, a simplified version of T2FLS is used. IT2FLS provides very manageable computation making it quite practical. Recently, T2FLSs and IT2FLSs are applied as useful techniques to handle all forms of uncertainties both in classification, prediction and control and the results are promising and very encouraging [22-33]. Consequently, IT2FLSs are widely applied in various areas because of their abilities to simplify type- 2 fuzzy logic controllers (T2FLCs) [34-36].

An IT2FLS is made up of five components namely, fuzzifier, rule base, inference engine, typereduction and defuzzifier. An iterative Karnik-Mendel (KM) algorithm can be explored to perform type-reduction. An extended version of type-1 defuzzification operation technique is usually applied on T2FSs case of the IT2FLS to obtain a T1FS at the output. The T1FS so obtained becomes a type-reduced set which is a collection of the outputs of all of the embedded T1FLSs [25]. However, Karnik-Mendel (KM) algorithm is computationally complex, timeconsuming with computational overhead which can reduce the real-time performance of the IT2FLS and also limit their application in industrial embedded controllers. To overcome the limitations of IT2FLS in order to speed up a T2FLC, Wu and Mendel uncertainty bounds (UB) technique is employed to approximate the type-reduced set instead of using KM algorithm [37][23]. This approach is believed to reduce the computation cost of the type-reduction and the memory required for the IT2FLS implementation.

This paper presents an intelligent call admission controller for 4G network using IT2FL for providing guaranteed QoS requirements. The IT2FLS with fuzzy membership functions can fully cope with uncertainties associated with such dynamic network environment by raising its accuracy for a better performance. The admission decisions are made based on system parameters like latency, packet loss, load, signal strength, and user mobility. The study employs K-M 
algorithm to obtain the type-reduced sets, and Wu-Mendel uncertainty bound approach for approximation of type-reduced set to estimate the uncertainty and crisp output of an IT2FLC. The remainder of the paper is given as follows; Section 2 presents an overview of interval type-2 fuzzy logic. In section 3, an intelligent call admission controller for guaranteed QoS in a 4G mobile network is presented. Results and discussion are given in section 4, while conclusion of the paper is presented in section 5 .

\section{AN OVERVIEW OF INTERVAL TYPE-2 FuZZY LOGIC}

\subsection{INTERVAL TYPE-2 FUZZY SETS}

According to [38], an interval type-2 fuzzy set (IT2FS) Ã is characterized as in (1):

$$
\tilde{\mathrm{A}}=\left\{\left((\mathrm{x}, \mathrm{u}), \mu_{\tilde{\mathrm{A}}}(\mathrm{x}, \mathrm{u})\right) \mid \forall \mathrm{x} \in \mathrm{X}, \forall \mathrm{u} \in \mathrm{J}_{\mathrm{x}} \subseteq[0,1]\right\}
$$

where $x$, the primary variable, has domain $X ; u \in U$, the secondary variable, has domain $\mathrm{J}_{\mathrm{x}}$ at each $x \in X ; \mathrm{J}_{\mathrm{x}}$ is called the primary membership of $\mathrm{x}$ and the secondary grades of $\tilde{\mathrm{A}}$ all equal 1 [39].

Uncertainty about $\tilde{A}$ is conveyed by the union of all the primary memberships, which is called the footprint of uncertainty (FOU) of $\tilde{A}$ as shown in (2) and Figure 1.

$$
\mu_{\tilde{\mathrm{A}}}(\mathrm{x}, \mathrm{u})=1, F O U(\tilde{\mathrm{A}})=U_{\forall \mathrm{x} \in \mathrm{X}} \mathrm{J}_{\mathrm{x}}=\{(\mathrm{x}, \mathrm{u}): \mathrm{u} \in \mathrm{Jx} \subseteq[0,1]\}
$$

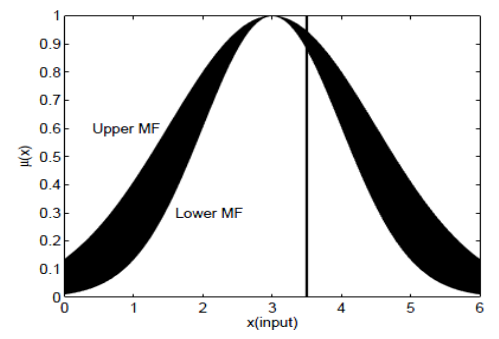

Fig 1: Interval Type-2 Fuzzy set [27]

The upper membership function (UMF) and lower membership function (LMF) of $\tilde{A}$ are two type1 MFs that bound the FOU as represented in (3) and (4).

$$
\begin{aligned}
& \mathrm{UMF}=\bar{\mu}_{\tilde{\mathrm{A}}}(\mathrm{x}) \equiv \overline{F O U(\tilde{\mathrm{A}})} \quad \forall x \in X \\
& \mathrm{LMF}=\underline{\mu}_{\tilde{\mathrm{A}}}(\mathrm{x}) \equiv \underline{\operatorname{FOU}(\tilde{\mathrm{A}})} \forall x \in X \\
& \mathrm{~J}_{\mathrm{x}}=\left\{(\mathrm{x}, \mathrm{u}): \mathrm{u} \in\left[\underline{\mu}_{\tilde{\mathrm{A}}}(\mathrm{x}), \bar{\mu}_{\tilde{\mathrm{A}}}(\mathrm{x})\right]\right\}
\end{aligned}
$$

where $\mathrm{J}_{\mathrm{X}}$ is an interval set. We can apply set theory operations of union, intersection and complement to easily compute for IT2FSs

\subsection{INTERVAL TYPE-2 FUZZY LOGIC SYSTEMS}

Figure 2 represents an IT2FLS architecture, which is a FLS that uses at least one IT2FS. It is characterized by five components, viz; a rule-base, a fuzzification unit, an inference-engine unit, type-reduction (TR) and defuzzification units - that are inter-connected. 


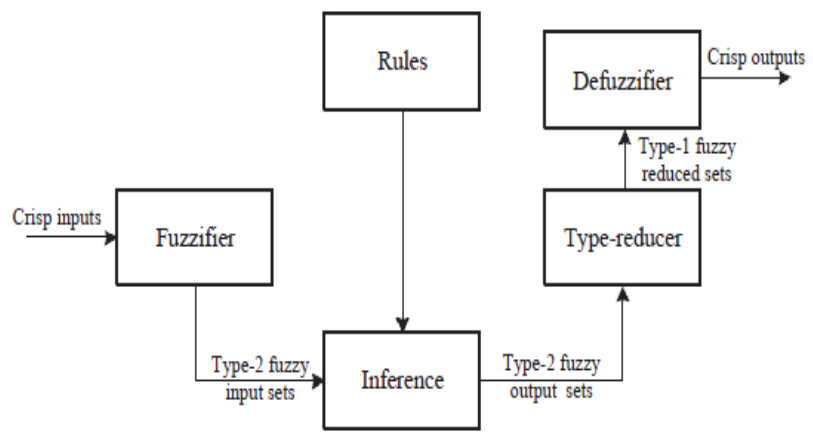

Fig. 2: Architecture of IT2FLS [27]

The IT2FL architecture updates a T1FS by adding the type reduction component. The fuzzifier maps a crisp input vector into T1 or IT2FSs using singleton fuzzifier. Input IT2FSs then activate the inference engine and the rule base to produce output IT2FSs. A TR unit combines the output sets and then performs a centroid calculation which produces an interval T1FS (type-reduced set). The TR set is then processed by the defuzzifier to produce crisp outputs. The rules, supplied by experts or extracted from numerical data can be expressed as a collection of IF-THEN statements. In IT2FLS, the rule can have $m$ inputs and $n$ outputs or $m$ inputs and one output as the later is specified as in (6).

$$
+ \text { IF } x_{i} \text { is } \tilde{A}_{i}^{l} A N D, \ldots, A N D x_{m} \text { is } \tilde{A}_{m}^{l} \text { THEN y is } \tilde{B}^{l}
$$

where $x_{i}, i=1, \ldots, m$ are the antecedents, $y$ is the consequent of the $l$ th rule of IT2FLS. The $\tilde{A}^{i}$ 's are the MFs $\mu_{\tilde{A}_{i}^{l}}\left(x_{i}\right)$ of the antecedent part assigned of the $i$ th input $x_{i}$, The $B^{l}$ is the MFs $\mu_{\tilde{B}_{j}^{l}}(y)$ of the consequent part assigned to the output $y_{j}$. The result of the input and antecedent operations contained in the firing set produces an interval type- 1 set as shown in (7) [26].

$$
F^{i}\left(x^{\prime}\right)=\left[\underline{f^{\prime}}\left(x^{\prime}\right), \overline{f^{\prime}}\left(x^{\prime}\right)\right] \equiv\left[f^{\prime}, \overline{f^{\prime}}\right]
$$

where $F^{i}\left(x^{\prime}\right)$ is the antecedent of rule $i$ and $\mu_{F 1}{ }^{i}\left(x^{\prime}\right)$ is the degree of membership of $x$ in $\mathrm{F}$. $\bar{\mu}_{\tilde{f}^{i}}(\mathrm{x})$ and $\underline{\mu}_{\tilde{f}^{i}}(\mathrm{x})$ are upper and lower MFs of $\mu_{\tilde{f}^{i}}, i=1$ to $m$ respectively. The inference engine combines the fired rules and gives a mapping from input to output in IT2FSs. The combined output fuzzy set, $\mu_{\tilde{E}_{j}^{l}}\left(y_{j}\right)$, is obtained by combining the fired output consequent sets by taking the union of the lth rule fired output consequent sets.

There are two ways to perform type-reduction: firstly, by iterative KM procedure to calculate the type-reduced fuzzy sets [25], while the second way is by $\mathrm{Wu}$ - Mendel uncertainty bounds method, employed to approximate the type-reduced set [38]. After the TR process, the type-reduced sets or the approximate type-reduced sets are then defuzzified to obtain crisp outputs that determine the level of call admittance factor in our case.

\subsection{AN IT2FLS USING KM ALgORITHM}

Five different TR techniques are described in [39], where the type-reduced set gives an interval of uncertainty for the output of an IT2FLS. IT2FS are characterized by their left- and right-end 
points required to compute the centroid of an IT2FS. An exact KM iterative method of TR is performed to compute the type-reduced sets of an IT2FS which is a T1FS [23] [25] [41] [42]. TR center-of-sets (COS) process can all be expressed in [27] [29] as

$Y_{T R}\left(x^{\prime}\right)=\left[y_{l}\left(x^{\prime}\right), y_{r}\left(x^{\prime}\right)\right] \equiv\left[y_{l}, y_{r}\right]=\int_{y^{1} \in\left[y_{l}^{1}, y_{r}^{1}\right]} \cdots \int_{y^{1} \in\left[y_{l}^{N}, y_{r}^{N}\right]} \int_{f^{1} \in\left[\underline{f}^{1}, \bar{f}^{1}\right]^{\prime}} \cdot \int_{f^{N} \in\left[\underline{f}^{N}, \bar{f}^{N}\right]} 1 /$

$\frac{\sum_{i=1}^{N} f^{i} y^{i}}{\sum_{i=1}^{N} f^{i}}$

where $y_{l}^{i}$ and $y_{r}^{i}$ are the left and right end points of the centroid of the consequent of the $i$ th rule while $f^{i}$ and $\bar{f}^{i}$ are the lower and upper firing degrees of the $i$ th rule and $N$ is the number of fired rules.

In this paper, KM Algorithms [41] is applied to compute the end-points exactly and are presented in (9) and (10) and the defuzzified crisp output for each output $k$ is achieved by averaging $y_{l k}$ and $\mathrm{y}_{\mathrm{rk}}$, in (11).

$$
\begin{gathered}
y_{r}=\frac{\sum_{i=1}^{N} f_{r}^{i} y_{r}^{i}}{\sum_{i=1}^{N} f_{r}^{i}} \\
y_{l}=\frac{\sum_{i=1}^{N} f_{l}^{i} y_{l}^{i}}{\sum_{i=1}^{N} f_{l}^{i}} \\
Y_{k}(X)=\frac{y_{l k}+y_{r k}}{2}
\end{gathered}
$$

\subsection{AN IT2FLS USING WM UNCERTAINTY BOUNDS}

The type-reduction (TR) is computationally intensive, time-consuming and associated with output uncertainty for a real-time application of an IT2FLS. However, to overcome the limitations of IT2FLS in order to speed up a T2FLC, Wu-Mendel uncertainty bounds technique is employed to approximate the type-reduced set. The inner- and outer-bound sets (called minimax uncertainty bounds) are provided for the type-reduced set to estimate the output uncertainty of IT2FLS and directly perform defuzzification to obtain output under certain conditions. These uncertainty bounds are $\underline{y}_{l}\left(x^{\prime}\right), \bar{y}_{l}\left(x^{\prime}\right), \underline{y}_{r}\left(x^{\prime}\right)$, $\bar{y}_{r}\left(x^{\prime}\right)$ as expressed in details in [38], where $\underline{y}_{l}\left(x^{\prime}\right) \leq y_{l}\left(x^{\prime}\right) \leq \bar{y}_{l}\left(x^{\prime}\right)$ and $\underline{y}_{r}\left(x^{\prime}\right) \leq$ $y_{r}\left(x^{\prime}\right) \leq \bar{y}_{r}\left(x^{\prime}\right)$. The type-reduction sets are approximated in (12) without having to perform TR. Defuzzification is performed directly in (13) to obtain the output [23][38].

$$
\left.\left.\left[y_{l}(x), y_{r}(x)\right] \approx\left[\underline{\left(y_{l}\right.}(x)+\bar{y}_{l}(x)\right) / 2, \underline{y_{r}}(x)+\bar{y}_{r}(x)\right) / 2\right]
$$

The output of IT2FLS is given as;

$$
y(x)=\frac{1}{2}\left[y_{l}(x), y_{r}(x)\right]=\frac{1}{2}\left[\left(y_{l}(x)+\bar{y}_{l}(x)\right) / 2+\left(\underline{y_{r}}(x)+\bar{y}_{r}(x)\right) / 2\right]
$$

\subsection{ADVANTAGES OF IT2FL OVER T1FLC}

The advantages T2FS over T1FS in representing the inputs and outputs of a FLC are summarized as: 
International Journal on Soft Computing (IJSC) Vol.8, No. 3/4, November 2017

(i) T2FL applications based on T2FS have the ability to handle the numerical and linguistic uncertainties associated with the inputs and outputs of a FLC because, T2FSs MFs are themselves fuzzy with an FOU, thus, can offer a better performance than T1FLC.

(ii) With T2FSs, there is a reduction in the rule base size than using T1FSs due to the uncertainty represented in the FOU in T2FSs which provides coverage of the same range as T1FSs with a smaller number of labels. Also, we tend to experience more relative reduction when there is an increase in FLCs [23] [34].

(iii) In T2FLC, input and output are represented by a large number of T1FSs which are embedded in the T2FSs [33]. This allows for a detailed description of the analytical control surface, a much smoother control surface and a response is achieved with the addition of the extra levels of classification [34].

(iv) Given the same number of MFs, FOU in T2FSs allows a T2FLC to provide provide outputs that cannot be achieved by T1FLCs in many applications. This is because of the extra degrees of freedom provided by the T2Fs, thus, allows a T2FLC to model more complex systems than T1FLC with a better control response [26].

\section{An INTElligent Call Admission Controller for guaranteed QOS IN 4G MOBILE NETWORKS}

\subsection{IT2FL-CAC MODEL}

The IT2FL-CAC model for improved QoS in 4G mobile networks is shown in Figure 3. Due to computational intensiveness of general T2FLSs [43], IT2FL controller, as discussed in this work, is employed to reduce the computational burden of T2FLS and an intelligently control call admission parameters in order to guarantee an improved QoS in 4G mobile networks. The choice of this technique lies in its ability of IT2FLS to fully cope with uncertainty associated with variables used in connection admission decision compared to T1FL model. Based on the impact of QoS parameters, connection admission factor (CAF) is determined for an effective decision on call admission and proper management of network's resources in the 4G mobile environment.

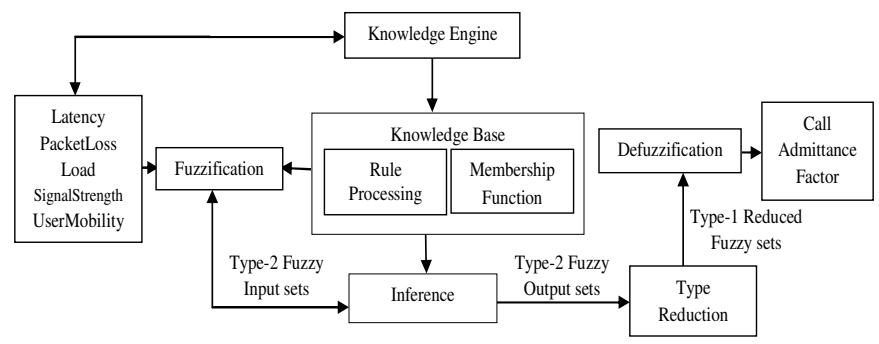

Fig. 3: The IT2FL-CAC model for call admission control

The model in Figure 3 is made up of five components: fuzzification, knowledge engine, inference, type-reduction and defuzzification. The system makes use of five inputs and one output variables which include, latency (LA), Packet Loss (PL), Signal Strength (SS), Load (LD), User Mobility (UM) and Call Admittance Factor (CAF) respectively, where the input parameters are obtained from the knowledge engine. CAF determines the degree of acceptability or otherwise of call request. 


\subsection{FUZZIFICATION}

In this work, fuzzy inputs are converted and fuzzified into input IT2F sets, and then are mapped to the linguistic labels of fuzzy sets to determine their degree of membership. Fuzzification is carried out using five input fuzzy linguistic variables, defined as latency $(L A)$, packet loss $(P L)$, signal strength $(S S)$, Load $(L D)$, and user mobility $(U M)$. The linguistic terms are also defined for the five input parameters as; Low $(L)$, Medium $(M)$, High $(H)$, Very Low $(V L)$, Low $(L)$, High $(H)$, Very High $(V H)$, Weak $(W)$, Moderate $(M)$, and Strong $(S)$ respectively. The MFs of these fuzzy sets contain five inputs and one output. We explore the use of MATLAB tool in MF plots as shown in Figures 9(a) - (e). The output variable (CAF) is defined with four linguistic terms; Poor $(P)$, Fair $(F)$, Good $(G$,$) and Excellent (E)$, and presented in Figure 4.The MF limits are selected based on input parameters and applied for reducing footprint of uncertainties. We consider IT2 Gaussian MFs with uncertain width (deviation) in (14) because it is suitable for highly dynamic random networks such as $4 \mathrm{G}$. The $\sigma \in\left[\sigma_{1}, \sigma_{2}\right]$ with upper and lower membership functions are defined in (15) and (16).

$$
\begin{aligned}
& f(x)=\exp \left(-\frac{x-c}{2 \sigma^{2}}\right), \sigma \in\left[\sigma_{1}, \sigma_{2}\right] \text { and } c \in\left[c_{1}, c_{2}\right] \\
& \bar{\mu}_{\tilde{\AA}_{i m}}\left(x_{i}\right)=\exp \left(-\frac{x_{i}-c_{i m}}{2 \bar{\sigma}_{2, i m}^{2}}\right), \bar{\mu}_{\tilde{A}}(x)=N\left(c, \sigma_{2} ; x\right) \\
& \underline{\mu}_{\tilde{A}_{i m}}\left(x_{i}\right)=\exp \left(-\frac{x_{i}-c_{i m}}{2 \underline{\sigma}_{1, i m}^{2}}\right), \underline{\mu}_{\tilde{A}}(x)=N\left(c, \sigma_{1} ; x\right)
\end{aligned}
$$

where $\mathrm{c}$ is the center (mean) of the MF, $\sigma$ is the width (standard deviation) of the MF and $x$ is the input vector. The variables $\bar{\sigma}_{2, i m}$ and $\underline{\sigma}_{1, i m}$ are premise parameters that define the degree of membership of each element to the fuzzy set $\tilde{A}$ and FOUs of the IT2IFS. The detail description is found in [33] [23]. MFs are defined and evaluated for all the input and output linguistic variables. IT2FSs are explored in the antecedent parts and each MF of the antecedent part is represented by an upper and a lower MF, denoted by $\bar{\mu}_{\tilde{\mathrm{A}}}(\mathrm{x})$ and $\underline{\mu}_{\tilde{\mathrm{A}}}(\mathrm{x})$ as described in [33]. Each node output indicates the lower and upper interval.

\subsection{Fuzzy Rules}

Fuzzy rules are defined based on (6), typically illustrated as; IF Latency is High and Packet Loss is Moderate and Load is High and Signal Strength is Strong and User Mobility is Low THEN CAF is FAIR $=[0.32,0.29]$. Rules are defined based on human expert opinion with 243 rules for the IT2FLC - CAC. For simplicity, parts of the rules are presented in Table 1. In the IT2FLS, the rule base part are enclosed with five antecedents ( $L A, P L, S S, L D, U M)$ which divide the input space into a set of fuzzy regions and one consequent (CAF) part which describes the system behavior in those regions. Each MF of the antecedent part is represented by an upper and a lower membership function.

Table 1: The IT2FL -CAC Fuzzy Rules

\begin{tabular}{lllllll}
\hline S/N & Latency & Packet Loss & Load & Signal Strength & User Mobility & CAF \\
\hline $\mathbf{1}$ & L & L & VL & W & H & EXCELLENT \\
$\mathbf{2}$ & H & H & VH & S & L & FAIR \\
$\mathbf{3}$ & H & H & VH & S & L & FAIR \\
$\mathbf{4}$ & L & M & VL & W & H & EXCELLENT \\
$\mathbf{5}$ & L & H & VL & W & H & GOOD \\
$\mathbf{6}$ & L & L & VL & W & H & EXCELLENT \\
\hline
\end{tabular}


International Journal on Soft Computing (IJSC) Vol.8, No. 3/4, November 2017

\begin{tabular}{|c|c|c|c|c|c|c|}
\hline & $\mathrm{L}$ & $\mathrm{M}$ & VL & $\mathrm{W}$ & $\mathrm{H}$ & GOOD \\
\hline 8 & $\mathrm{~L}$ & $\mathrm{H}$ & VL & W & $\mathrm{H}$ & GOOD \\
\hline 9 & M & $\mathrm{L}$ & VL & W & $\mathrm{H}$ & GOOD \\
\hline 10 & M & M & VL & W & $\mathrm{H}$ & GOOD \\
\hline 11 & M & $\mathrm{H}$ & VL & W & $\mathrm{H}$ & GOOD \\
\hline 12 & $\mathrm{H}$ & $\mathrm{L}$ & VL & W & $\mathrm{H}$ & GOOD \\
\hline 13 & $\mathrm{H}$ & M & VL & W & $\mathrm{H}$ & GOOD \\
\hline 14 & $\mathrm{H}$ & $\mathrm{H}$ & VL & W & $\mathrm{H}$ & FAIR \\
\hline 15 & $\mathrm{H}$ & $\mathrm{L}$ & VL & W & $\mathrm{H}$ & GOOD \\
\hline 16 & $\mathrm{H}$ & M & VL & W & $\mathrm{H}$ & FAIR \\
\hline 17 & $\mathrm{H}$ & $\mathrm{H}$ & VL & W & $\mathrm{H}$ & FAIR \\
\hline 18 & $\mathrm{~L}$ & M & $\mathrm{L}$ & M & M & EXCELLENT \\
\hline 19 & $\mathrm{~L}$ & $\mathrm{H}$ & $\mathrm{L}$ & M & M & GOOD \\
\hline 20 & $\mathrm{~L}$ & M & $\mathrm{L}$ & M & M & GOOD \\
\hline . & . & . & . & . & . & \\
\hline 43 & $\mathrm{H}$ & $\mathrm{L}$ & VH & W & $\mathrm{H}$ & FAIR \\
\hline 44 & $\mathrm{H}$ & M & VH & W & $\mathrm{H}$ & POOR \\
\hline 45 & M & M & $\mathrm{L}$ & S & $\mathrm{L}$ & GOOD \\
\hline
\end{tabular}

\subsection{FUZZY INFERENCE}

Here, inference engine combines fired rules, maps input IT2FSs and output IT2FSs by computing unions and intersections of type- 2 sets, as well as compositions of type- 2 relations. The main problem is to determine the effect of input parameters in the antecedent part such that a concise representation of the system's behavior is produced in the consequent part, i.e. network connection admission. This paper uses Mamdani fuzzy inference engine to calculate the firing strengths of the $l$ th rule illustrated in (7). Two firing levels are then computed, including a lower firing level, $f^{\prime}\left(x^{\prime}\right)$, and an upper firing level $\overline{f^{\prime}}\left(x^{\prime}\right), f^{\prime}\left(x^{\prime}\right)=\min \left[\underline{\mu}_{\tilde{A}_{1}}\left(x_{1}\right), \underline{\mu}_{\tilde{A}_{2}}\left(x_{1}\right)\right]$ and $\overline{f^{\prime}}\left(x^{\prime}\right)=\min \left[\bar{\mu}_{\tilde{A}_{1}}\left(x_{1}\right), \bar{\mu}_{\tilde{\AA}_{2}}\left(x_{1}\right)\right]$. The firing interval $F(x)$, which is the main observation, is the result of input and antecedent operation, where $\bar{F}(x)=[f(x), \bar{f}(x)]$.

\subsection{TYPE REDUCTION AND DEFUZZIFICZTION}

Type reducer maps IT2-FS into a T1FS by combining the fuzzy output sets (IT1FS). In our paper, IT2FLC-CAC employs center-of-sets type-reduction [45] to compute the two end points $\left(\mathrm{y}_{1}\right.$ and $\mathrm{y}_{\mathrm{r}}$ ) of centroids of the M consequent of IT2FSs using the KM algorithms illustrated in section 2.4 of this paper, to produce the correct values of type-reduced sets. Defuzzification is carried out by mapping the T1FS into a crisp number. Here, the interval output for each node present in computed respectively. The final output of T2FLS-CAC, which is a numeric value, is obtained by averaging the output of the resultant effect of the four embedded T1FLS using (10).

However, it is observed that KM TR scheme shows a major bottleneck using an interval type- 2 FLS in real-time practices. Wu-Mendel uncertainty bounds approximation method is employed, to estimate the type-reduced sets and determine the output of the FLS directly in order to eliminate type-reduction. The WM model is described in section 2.5 of this paper.

Next, we present our model experiments and discuss of simulation results. We use the root mean square error (RMSE) performance criterion for our experiments which is defined as: 


$$
R M S E=\sqrt{\frac{1}{N} \sum_{i=1}^{N}\left(y^{x}-y\right)^{2}}
$$

Where $y^{x}$ is the desired output, $\mathrm{y}$ is our model output and $\mathrm{N}$ is the number of data items.

\section{MODEL EXPERIMENT RESUlTS}

In this paper, an intelligent IT2FL-CAC using KM type-reduction and Wu-Mendel UB methods are applied to guarantee QoS provisioning in $4 \mathrm{G}$ mobile networks. In order to illustrate the methodology proposed in this paper, we conduct some experiments for CAC in $4 \mathrm{G}$ networks described in this work. The universe of discourse is defined for the linguistic variables as shown in Table 2. The membership matrices' for the various levels of crisp inputs for our IT2FLS are presented in Tables 3-7. 200 datasets are generated based on the input variables $L A, P L, S S, L D$, and $U M$ and $C A F$ is the desired output. For each input, Gaussian MFs with fixed mean and uncertain standard deviation is employed for MF evaluation. For example, given the crisp input vector $\mathrm{v}=[20,2,50,-94,2]$, their degrees of membership are calculated as shown in Table 8. Evaluating fired rules 20, 22, 30, 32, 45 against the fuzzy set yields the firing level and the results are presented in Table 9.

Table 2: The Universe of Discourse defined for the linguistic variables

\begin{tabular}{|l|l|l|l|l|l|}
\hline \multicolumn{7}{|c|}{ Input Variables and their Universe of Discourse } \\
\hline $\begin{array}{l}\text { Latency } \\
(\mathrm{LA})\end{array}$ & $\begin{array}{l}\text { Packet } \\
\text { Loss (PL) }\end{array}$ & $\begin{array}{l}\text { Signal Strength } \\
(\mathrm{SS})(\mathrm{dBm})\end{array}$ & $\begin{array}{l}\text { Load } \\
(\mathrm{LA})\end{array}$ & $\begin{array}{l}\text { User Mobility } \\
(\mathrm{UM})(\mathrm{m} / \mathrm{s})\end{array}$ & $\begin{array}{l}\text { Call Admittance } \\
\text { Factor (CAF) }\end{array}$ \\
\hline$[0,100]$ & {$[0,5]$} & {$[-100,-80]$} & {$[0,100]$} & {$[0,6]$} & {$[0,1]$} \\
\hline
\end{tabular}

Table 3: Membership matrix for Latency

\begin{tabular}{|l|l|l|l|l|l|l|}
\hline Fuzzy & \multicolumn{5}{|c|}{ Crisp Input } \\
\cline { 2 - 7 } $\operatorname{Set}\left[\bar{\mu}^{1}, \underline{\mu}^{1}\right]$ & 10 & 20 & 40 & 60 & 80 & 100 \\
\hline $\mathrm{L}$ & {$[0.3,0.08]$} & {$[1.0,1.0]$} & {$[0.008,0.0]$} & {$[0.0,0.0]$} & {$[0.0,0.0]$} & {$[0.0,0.0]$} \\
\hline $\mathrm{M}$ & {$[0.0,0.0]$} & {$[0.01,0.001]$} & {$[0.6,0.5]$} & {$[0.6,0.5]$} & {$[0.01,0.001]$} & {$[0.0,0.0]$} \\
\hline $\mathrm{H}$ & {$[0.0,0.0]$} & {$[0.0,0.0]$} & {$[0.0,0.0]$} & {$[0.008,0.0]$} & {$[1.0,1.0]$} & {$[0.008,0.0]$} \\
\hline
\end{tabular}

Table 4: Membership matrix for Packet Loss

\begin{tabular}{|l|l|l|l|l|l|l|}
\hline $\begin{array}{l}\text { Fuzzy } \\
\text { Set }\left[\bar{\mu}^{2}, \underline{\mu}^{2}\right]\end{array}$ & \multicolumn{6}{|c|}{ Crisp Input } \\
\cline { 2 - 7 } & 0 & 1 & 2 & 3 & 4 & 5 \\
\hline L & {$[1.0,1.0]$} & {$[0.45,0.24]$} & {$[0.04,0.003]$} & {$[0.0,0.0]$} & {$[0.0,0.0]$} & {$[0.0,0.0]$} \\
\hline M & {$[0.0,0.0]$} & {$[0.003,0.0]$} & {$[0.53,0.36]$} & {$[0.53,0.36]$} & {$[0.003,0.0]$} & {$[0.0,0.0]$} \\
\hline H & {$[0.0,0.0]$} & {$[0.0,0.0]$} & {$[0.0,0.0]$} & {$[0.043,0.003]$} & {$[0.45,0.24]$} & {$[1.0,1.0]$} \\
\hline
\end{tabular}


International Journal on Soft Computing (IJSC) Vol.8, No. 3/4, November 2017

Table 5: Membership matrix for Load

\begin{tabular}{|l|l|l|l|l|l|}
\hline \multirow{2}{*}{$\begin{array}{l}\text { Suzzy } \\
\operatorname{Set}\left[\bar{\mu}^{3}, \underline{\mu}^{3}\right]\end{array}$} & \multicolumn{5}{|c|}{ Crisp Input } \\
\cline { 2 - 6 } & 10 & 30 & 50 & 70 & 90 \\
\hline VL & {$[0.36,0.13]$} & {$[0.36,0.13]$} & {$[0.0,0.0]$} & {$[0.0,0.0]$} & {$[0.0,0.0]$} \\
\hline L & {$[0.0]$,} & {$[0.45,0.24]$} & {$[0.45,0.24]$} & {$[0.0,0.0]$} & {$[0.0,0.0]$} \\
\hline H & {$[0.0,0.0]$} & {$[0.0,0.0]$} & {$[0.36,0.13]$} & {$[0.36,0.13]$} & {$[0.0,0.0]$} \\
\hline VH & {$[0.0,0.0]$} & {$[0.0,0.0]$} & {$[0.0,0.0]$} & {$[0.36,0.13]$} & {$[0.36,0.13]$} \\
\hline
\end{tabular}

Table 6: Membership matrix for Signal Strength

\begin{tabular}{|l|l|l|l|l|l|}
\hline Fuzzy & \multicolumn{5}{|c|}{ Crisp Input } \\
\cline { 2 - 6 } $\operatorname{Set}\left[\bar{\mu}^{4}, \underline{\mu}^{4}\right]$ & -96 & -94 & -90 & -85 & -82 \\
\hline W & {$[0.84,0.70]$} & {$[0.84,0.70]$} & {$[0.013,0.0]$} & {$[0.0,0.0]$} & {$[0.0,0.0]$} \\
\hline M & {$[0.001,0.0]$} & {$[0.06,0.003]$} & {$[1.0,1.0]$} & {$[0.013,0.0]$} & {$[0.0,0.0]$} \\
\hline S & {$[0.0,0.0]$} & {$[0.0,0.0]$} & {$[0.013,0.0]$} & {$[1.0,1.0]$} & {$[0.21,0.04]$} \\
\hline
\end{tabular}

Table 7: Membership function for User Mobility

\begin{tabular}{|l|l|l|l|l|l|}
\hline Fuzzy & \multicolumn{5}{|c|}{ Crisp Input } \\
\cline { 2 - 6 } $\operatorname{Set}\left[\bar{\mu}^{5}, \underline{\mu}^{5}\right]$ & 1 & 2 & 3 & 4 & 5 \\
\hline L & {$[0.45,0.24]$} & {$[0.04,0.0]$} & {$[0.0,0.0]$} & {$[0.0,0.0]$} & {$[0.0,0.0]$} \\
\hline M & {$[0.01,0.0]$} & {$[0.36,0.13]$} & {$[1.0,1.0]$} & {$[0.3,0.13]$} & {$[0.01,0.0]$} \\
\hline H & {$[0.0,0.0]$} & {$[0.0,0.0]$} & {$[0.0,0.0]$} & {$[0.04,0.0]$} & {$[0.45,0.24]$} \\
\hline
\end{tabular}

Table 8: Fuzzified Values

\begin{tabular}{|l|l|l|l|l|}
\hline \multicolumn{5}{|c|}{ Linguistic Variable } \\
\hline $\begin{array}{c}\text { Latency } \\
{\left[\bar{\mu}^{1}, \underline{\mu}^{1}\right]}\end{array}$ & $\begin{array}{c}\text { PacketLoss } \\
{\left[\bar{\mu}^{2}, \underline{\mu}^{2}\right]}\end{array}$ & $\begin{array}{c}\text { Signal } \\
{\left[\bar{\mu}^{3}, \underline{\mu}^{3}\right]}\end{array}$ & $\begin{array}{c}\text { Load } \\
{\left[\bar{\mu}^{4}, \underline{\mu}^{4}\right]}\end{array}$ & $\begin{array}{c}\text { Mobility } \\
{\left[\bar{\mu}^{4}, \underline{\mu}^{4}\right]}\end{array}$ \\
\hline$\mu_{\mathrm{L}}[1.0,1.0]$ & $\mu_{\mathrm{L}}[0.04,0.003]$ & $\mu_{\mathrm{VL}}[0.0,0.0]$ & $\mu_{\mathrm{W}}[0.84,0.70]$ & $\mu_{\mathrm{L}}[0.04,0.01]$ \\
\hline$\mu_{\mathrm{M}}[0.01,0.001]$ & $\mu_{\mathrm{M}}[0.53,0.36]$ & $\mu_{\mathrm{L}}[0.42,0.24]$ & $\mu_{\mathrm{M}}[0.06,0.003]$ & $\mu_{\mathrm{M}}[0.36,0.13]$ \\
\hline$\mu_{\mathrm{H}}[0.0,0.0]$ & $\mu_{\mathrm{H}}[0.0,0.0]$ & $\mu_{\mathrm{H}}[0.36,0.13]$ & $\mu_{\mathrm{S}}[0.0,0.0]$ & $\mu_{\mathrm{H}}[0.0,0.0]$ \\
\hline & & $\mu_{\mathrm{VH}}[0.0,0.0]$ & & \\
\hline
\end{tabular}

Table 9: Rule Evaluation

\begin{tabular}{|l|l|c|}
\hline $\begin{array}{c}\text { Rule } \\
\text { No. }\end{array}$ & \multicolumn{1}{|c|}{ Firing Interval } & \multicolumn{1}{|c|}{ Consequent } \\
\hline R20 & {$\left[\underline{f}^{1}, \bar{f}^{1}\right]==[0.000007,0.00013]$} & {$\left[\underline{y}^{1}, \bar{y}^{1}\right]=\operatorname{GOOD}[0.3,0.2]$} \\
\hline R22 & {$\left[\underline{f}^{2}, \bar{f}^{2}\right]==[0,0.0]$} & {$\left[\underline{y}^{2}, \bar{y}^{2}\right]=\operatorname{GOOD}[1.0,1.0]$} \\
\hline
\end{tabular}


International Journal on Soft Computing (IJSC) Vol.8, No. 3/4, November 2017

\begin{tabular}{|l|l|l|}
\hline R30 & {$\left[\underline{f}^{3}, \bar{f}^{3}\right]==[0.0012,0.0016]$} & {$\left[\underline{y}^{3}, \bar{y}^{3}\right]=\operatorname{GOOD}[0.3,0.2]$} \\
\hline R32 & {$\left[\underline{f}^{4}, \bar{f}^{4}\right]==[0,0.0]$} & {$\left[\underline{y}^{4}, \bar{y}^{4}\right]=\operatorname{GOOD}[1.0,0.9]$} \\
\hline R45 & {$\left[\underline{f}^{5}, \bar{f}^{5}\right]==[0,0.0]$} & {$\left[\underline{y}^{5}, \bar{y}^{5}\right]=\operatorname{GOOD}[0.3,0.2]$} \\
\hline
\end{tabular}

We perform type reduction by selecting our leftmost $(L)$ and rightmost $(R)$ points at $L=4$ and $R=$ 1 and compute the values of $y_{l}$ and $y_{r}$ in (18) and (19) and defuzzification is performed as presented in (20).

$$
\begin{aligned}
& y_{l}=\frac{\bar{f}^{1} \underline{y}^{1}+\bar{f}^{2} \underline{y}^{2}+\bar{f}^{3} \underline{y}^{3}+\bar{f}^{4} \underline{y}^{4}+\underline{f}^{5} \underline{y}^{5}}{\bar{f}^{1}+\bar{f}^{2}+\bar{f}^{3}+\bar{f}^{4}+\underline{f}^{5}}=0.33 \\
& y_{r}=\frac{f^{1} \bar{y}^{1}+\bar{f}^{2} \bar{y}^{2}+\bar{f}^{3} \bar{y}^{3}+\bar{f}^{4} \bar{y}^{4}+\bar{f}^{2} \bar{y}^{5}}{f^{1}+\bar{f}^{2}+\bar{f}^{3}+\bar{f}^{4}+\bar{f}^{5}}=0.32 \\
& Y_{k}(x)=(0.33+0.32) / 2=0.325
\end{aligned}
$$

We apply Wu-Mendel uncertainty bounds method to compute the TR set by its inner- and outerbound sets and approximate $\left[y_{l}(x), y_{r}(x)\right]$ to estimate the output uncertainty of an IT2FLS for the end-points of the TR set as shown in (18) - (24). The output of the FLS is calculated in (25).

$$
\begin{gathered}
\bar{y}_{l}=\frac{\bar{f}^{1} \bar{y}^{1}+\bar{f}^{2} \bar{y}^{2}+\cdots+\bar{f}^{n} \bar{y}^{n}}{\bar{f}^{1}+\bar{f}^{2}+\cdots+\bar{f}^{n}}=0.2 \\
\underline{y_{l}}=\frac{\bar{f}^{1} \underline{y}^{1}+\bar{f}^{2} \underline{y}^{2}+\cdots+\bar{f}^{n} \underline{y}^{n}}{\bar{f}^{1}+\bar{f}^{2}+\cdots+\bar{f}^{n}}=0.3 \\
\bar{y}_{r}=\frac{f^{1} \bar{y}^{1}+\bar{f}^{2} \bar{y}^{2}+\cdots+\bar{f}^{n} \bar{y}^{n}}{\underline{f}^{1}+\bar{f}^{2}+\cdots+\bar{f}^{n}}=0.2 \\
\bar{y}_{r}=\frac{\underline{f}^{1} \underline{y}^{1}+\bar{f}^{2} \underline{y}^{2}+\cdots+\bar{f}^{n} \underline{y}^{n 1}}{\underline{f}^{1}+\bar{f}^{2}+\cdots+\bar{f}^{n}}=0.3 \\
{\left[y_{l}(x), y_{r}(x)\right]=Y(x) \approx 0.25}
\end{gathered}
$$

The output of the system is described mathematically by;

$$
\text { Output }=\left\{\begin{array}{cr}
\text { POOR: } & \text { if output } \leq 25 \% \\
\text { FAIR: } & \text { if } 25 \%<\text { output } \leq 50 \% \\
\text { GOOD: } & \text { if } 50 \%<\text { output } \leq 75 \% \\
\text { EXCELLENT: } & \text { if output }>75 \%
\end{array}\right.
$$

A threshold of $50 \%$ is set in other to constrain the limits of acceptance values. A threshold is a value of a metric that should cause an alert to be generated or management action to be taken [46]. A threshold of 50\% and above indicates that network resources are available hence; a call can be accepted into the network.

\section{RESULTS AND DISCUSSION}

The intelligent IT2FL-CAC is simulated using two controllers: the IT2FL controller using KM type-reduction method and the IT2FL controller using WM method. Furthermore, we also implemented a T1FLS-CAC; thus an IT2FLS-AC and T1FLS-AC are implemented for 
comparison purposes. Fuzzy logic toolbox in Matlab 7.5.0 is used for the input and output MFs plots and presented in Figures 4(a)-(f). The system is developed using Java software development toolkit (SDK). The input form accepts fuzzy parameters from the user. These parameters are then passed to the fuzzification module of the system. The fuzzifier acts on the parameters to produce an IT2FS which is evaluated against the rules to produce yet another IT2FS. Type reduction and defuzzification are carried out to produce a crisp output that is displayed using a "TextField" component of the system. From Figure 5, the result shows a fair call admittance factor of $48 \%$ is achieved based on the level of influence of the inputs on the output. This indicates that the network does not have enough resources to admit the call i.e, the call is not accepted into the network. The results obtained from applying different approaches to the admission control process to guarantee efficient QoS are as shown in Table 10. Table 11 presents the comparison of IT2FLS-KM, IT2FLS-WM and ITIFLS in admission control in 4G networks and RMSE performance criterion for our experiment. The graph of the result of IT2FLS- CAC using KM approach is shown in Figure 6. Figure 7 gives the graph of the result of IT2FLS- CAC using WU approach, while Figure 8 presents the graph of the result of IT1FL-CAC.

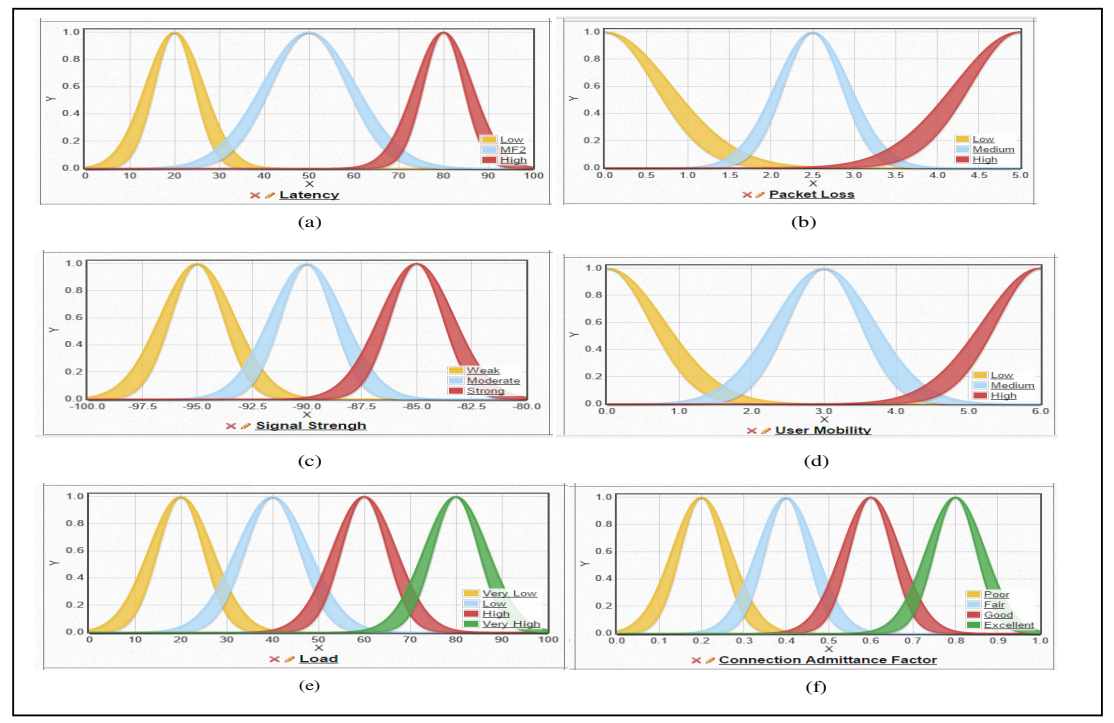

Fig. 4: (a) Latency (b) Packet Loss (c) Load (d) Signal Strength (e) User Mobility (input IT2 Membership Functions for) and (f) Output membership functions (CAF)

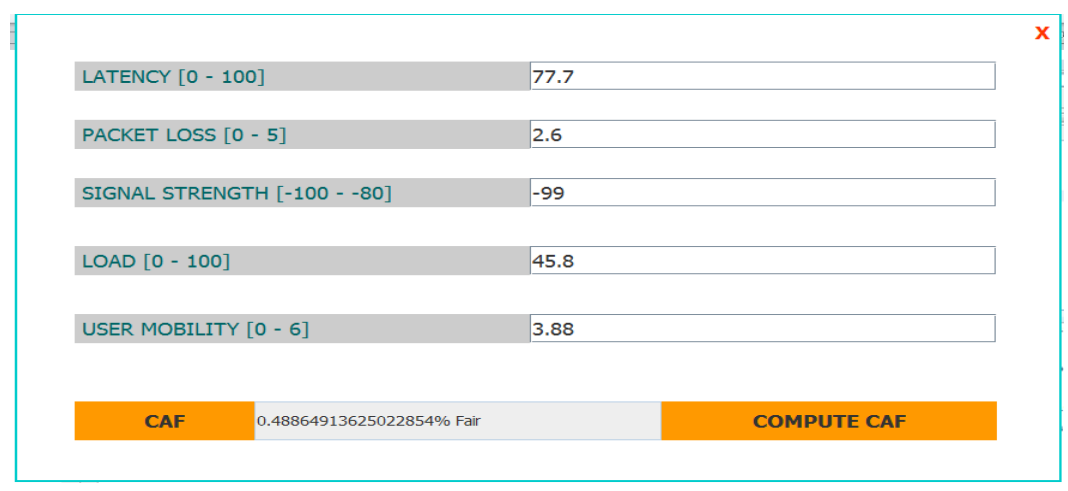

Figure 5: IT2FL-CAC Result 
International Journal on Soft Computing (IJSC) Vol.8, No. 3/4, November 2017

Table 10: IT2FL and IT1L CAC Experimental Results

\begin{tabular}{|c|c|c|c|c|c|c|c|c|c|c|}
\hline \multicolumn{11}{|c|}{ IT2FL and IT1FL Call Admission Results } \\
\hline \multirow[b]{2}{*}{$S / N$} & \multirow[b]{2}{*}{ Latency } & \multirow[b]{2}{*}{ Packet Loss } & \multirow[b]{2}{*}{ Load } & \multirow[b]{2}{*}{ Signal Strength } & \multirow[b]{2}{*}{ User Mobility } & \multirow[b]{2}{*}{$\mathrm{Yl}$} & \multirow[b]{2}{*}{$\mathrm{Yr}$} & \multicolumn{2}{|c|}{ IT2FL } & \multirow{2}{*}{$\begin{array}{c}\text { T1FL } \\
\text { IT1FL } \\
\end{array}$} \\
\hline & & & & & & & & $\mathrm{KM}$ & WU & \\
\hline 1 & 23.39761925 & 4.782493591 & 34.14649963 & \begin{tabular}{|l|}
-86.58191681 \\
\end{tabular} & 4.16469574 & 0.651729187 & 0.609048401 & 0.630388794 & 0.630167788 & 0.52 \\
\hline 2 & 59.13171005 & 4.835350037 & 29.49345016 & -93.16853333 & 2.212117672 & 0.99995877 & 0.992286656 & 0.996122713 & 0.996431759 & 0.65 \\
\hline 3 & 8.009558678 & 4.997141838 & 40.46202469 & -81.70938873 & 1.075722814 & 0.650119839 & 0.550421062 & 0.60027045 & 0.60407055 & 0.5 \\
\hline 4 & 28.88267708 & 1.556679249 & 0.618451834 & -98.71507263 & 2.57207346 & 0.814729847 & 0.787889404 & 0.801309625 & 0.80132129 & 0.75 \\
\hline 5 & 57.68119049 & 3.718532085 & 96.13624573 & -86.05348969 & 3.419070244 & 1 & 0.987392868 & 0.993696434 & 0.996129886 & 0.7 \\
\hline 6 & 36.49825287 & 0.467535853 & 84.23316956 & -99.67602539 & 3.332528591 & 0.999999834 & 0.899342281 & 0.949671058 & 0.949671055 & 0.75 \\
\hline 7 & 16.43228531 & 1.770384908 & 4.708766937 & -91.43685913 & 0.983432651 & 0.978162667 & 0.208230975 & 0.593196821 & 0.617159698 & 0.48 \\
\hline 8 & 91.47351074 & 3.671760082 & 76.3494873 & -98.97769928 & 0.544688702 & 0.624114712 & 0.821757072 & 0.722935892 & 0.733975238 & 0.7 \\
\hline 9 & 29.72520638 & 0.575915277 & 99.39528656 & -96.62104797 & 5.489224434 & 1 & 0.899624423 & 0.949812211 & 0.949812211 & 0.7 \\
\hline 10 & 37.83773804 & 4.140957355 & 46.00809097 & -97.79297638 & 4.743180275 & 0.999248616 & 0.393988832 & 0.696618724 & 0.702996027 & 0.55 \\
\hline 11 & 73.30070496 & 0.570019484 & 19.82002258 & -84.14083862 & 1.904493213 & 0.309896523 & 0.285087653 & 0.297492088 & 0.293975965 & 0.09 \\
\hline 12 & 90.50460815 & 1.187733412 & 48.80061722 & -81.58362579 & 3.851906776 & 0.659964457 & 0.645077075 & 0.652520766 & 0.652539482 & 0.8 \\
\hline 13 & 35.31845856 & 0.796303749 & 55.58693314 & -91.94580841 & 2.347836256 & 0.901271068 & 0.200206576 & 0.550738822 & 0.57220729 & 0.5 \\
\hline 14 & 25.81006813 & 2.981541395 & 35.22211456 & -99.78913116 & 3.002118587 & 0.667908269 & 0.608371366 & 0.638139818 & 0.638556624 & 0.6 \\
\hline 15 & 86.09112549 & 4.168234825 & 85.61044312 & -98.93075562 & 5.994147778 & 0.999999691 & 0.898933886 & 0.949466788 & 0.949511194 & 0.72 \\
\hline 16 & 44.31048584 & 4.547613144 & 66.90149689 & -84.54164886 & 4.623449326 & 0.99923982 & 0.999148899 & 0.99919436 & \begin{tabular}{|l|}
0.999193708 \\
\end{tabular} & 0.75 \\
\hline 17 & 57.17311478 & 4.864745617 & \begin{tabular}{|l|}
57.4464798 \\
\end{tabular} & -88.15919495 & 0.09990406 & 0.999997491 & 0.997864367 & 0.998930929 & 0.99901652 & 0.74 \\
\hline 18 & 48.1325798 & 2.806750536 & 97.74352264 & -84.34715271 & 3.428855419 & 0.999939181 & 0.201135766 & \begin{tabular}{|l|l|}
0.600537473 \\
\end{tabular} & 0.601496962 & 0.65 \\
\hline 19 & 8.453929901 & 3.228743553 & 57.91474152 & -85.3899765 & 4.550435066 & 0.650325384 & 0.600365801 & 0.625345592 & 0.625345593 & 0.43 \\
\hline 20 & 93.65468597 & 4.439779758 & 47.34951782 & -98.01423645 & 1.359944701 & 0.610046116 & 0.792653241 & 0.701349679 & 0.70554719 & 0.5 \\
\hline 21 & 92.99415588 & 2.921215534 & 77.52400208 & -86.62914276 & 0.583048224 & 0.999352784 & 0.884940483 & 0.942146633 & 0.943375959 & 0.72 \\
\hline $3 n$ & & & & 0272710770 & & & & & 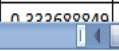 & \\
\hline
\end{tabular}

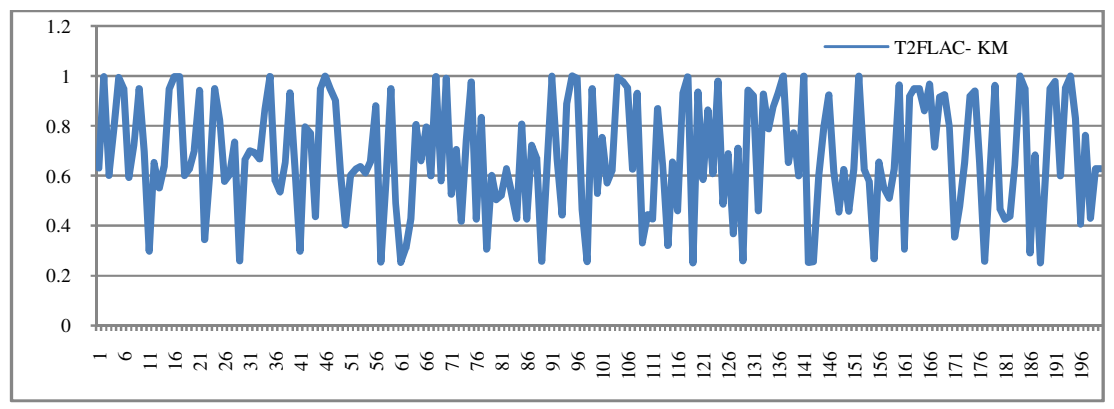

Fig. 6: Graph of the result of Interval Type-2 Fuzzy Logic Admission Control using KM approach

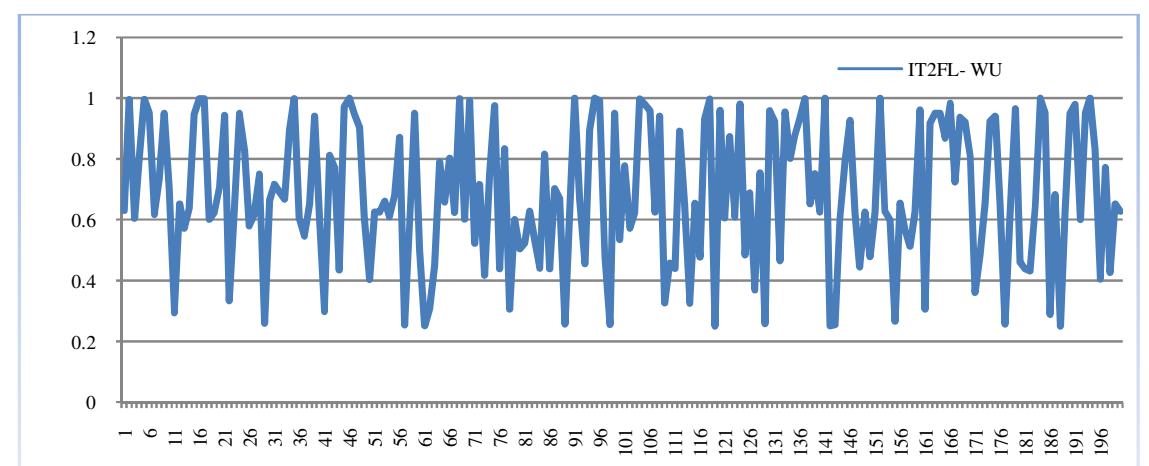

Fig. 7: Graph of the result of Interval Type-2 Fuzzy Logic Admission Control using WU approach 


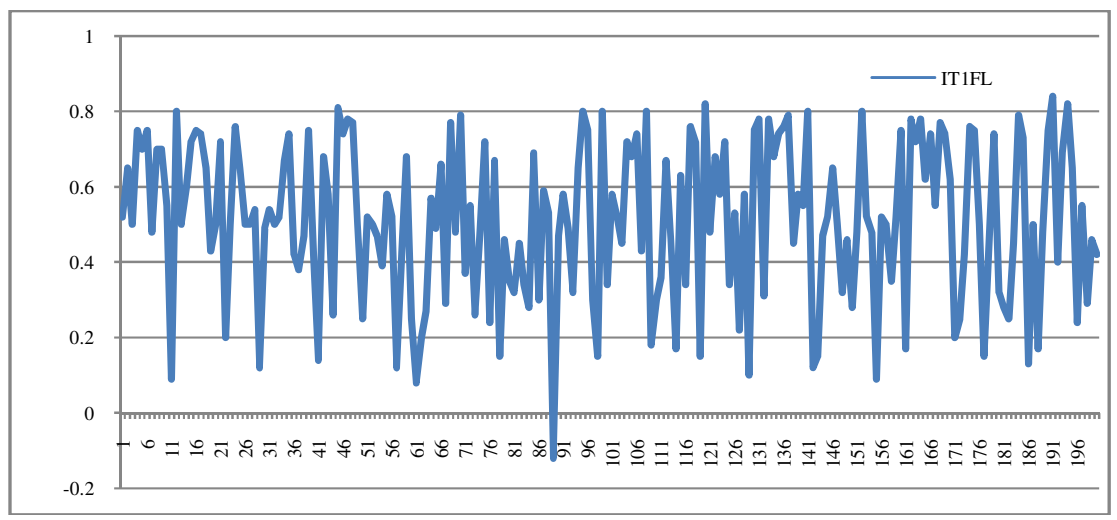

Fig. 8: Graph of the result of Interval Type-1 Fuzzy Logic Admission Control

Table 11: Comparison of IT2FLS-KM, IT2FLS-UM and ITIFLS in Admission Control in 4G Networks

\begin{tabular}{|l|l|l|l|l|}
\hline Models & Training/Chk & Mean & $\begin{array}{l}\text { Standard } \\
\text { Deviation }\end{array}$ & $\begin{array}{l}\text { Root Mean Square } \\
\text { Error (RMSE) }\end{array}$ \\
\hline IT1FLAC & $400 / 200$ & 0.5123 & 58.6776 & 0.0456 \\
\hline IT2FLAC-KM & $400 / 200$ & 0.6789 & 51.5483 & 0.0021 \\
\hline IT2FLAC-WM & $400 / 200$ & 0.6876 & 48.2197 & 0.0016 \\
\hline
\end{tabular}

From the results, it generally indicates that IT2FLS-CAC using Wu-Mendel method outperforms $\mathrm{KM}$ on the same set of input parameters. For example, from Table 10, with 35\% 'low' latency, 0.79 'low' packet loss, 56\% 'low' load, -91.9 'very high' signal strength and 2 'moderate' user mobility factor, 57\% 'good' CAF is achieved using WU approach as against 55\% good CAF with KM method. From our results, it can be seen that though the KM procedure is proven to converge in no more than $M$ (number of fired rules, maximum four, if all rules fired) iterations to find the left endpoint of the type-reduced set and no more than $M$ iterations to find the right endpoint of the type-reduced sets, then the IT2FLS-CAC would take a maximum of eight iterations (which is an acceptable number) to finish the TR steps. But in this paper, where as large as 243 fuzzy rules considered, it is not feasible to employ the M procedure and calculate a better result of the type-reduced sets. Rather an approximate type-reduced set using the Wu-Mendel uncertainty bounds method is employed to offer a better performance. However, it is observed that approximately $100 \%$ optimal value in terms of QoS demands and overall network performance is achieved using both approaches with 44\% 'medium' latency, 5\% 'high' packet loss, 67\% 'high' load, -85 'strong' signal strength and 5 'high' user mobility factor or 57\% latency, 4.9 packet loss, $57 \%$ load, -88.2 signal strength, and 0.1 user mobility factor.

From Table 11, it is observed that IT2FLS-CAC using WM gives 0.0016 RMSE, which outperforms IT2FLS-CAC using KM with 0.0021 RMSE. This is because the lower the error, the better the performance of the technique. We also implement a T1FLS in order to comparatively evaluate the performance of the IT2FLS-CAC with the T1FL model. The result indicates that IT2FLS-CAC outperforms T1FLS-CAC. This is as a result of the extra degrees of freedom offered by the FOUs of the IT2FLSs. The overall result shows a $1.62 \%$ improvement of IT2FLSCAC with WM over IT2FLS-CAC with KM and $87.07 \%$ over T1FLS-CAC. This indicates that there is a significant performance improvement of IT2FLS over T1FLS on system control.

\section{CONCLUSION}

In this study, an IT2FLS approach to control CAC for guaranteed QoS in $4 \mathrm{G}$ mobile networks is presented. The main problem is to determine the effect of input parameters in the antecedent part 
such that a concise representation of the system's behavior is produced in the consequent part, i.e. call connection admission. We have shown that IT2FLS-CAC using WM method outperforms $\mathrm{KM}$ on the same set of input parameters. The study indicates that IT2FLS-CAC outperforms T1FLS-CAC as a result of the extra degrees of freedom offered by the FOUs of the IT2FLSs. Key to this work is the ability to show that an IT2FLS-CAC can preserve all the qualities of an IT1FLS-CAC and still respond to uncertainty in the packet delay measurements in $4 \mathrm{G}$ networks. The IT2FLS can accommodate more imprecision thereby modeling imperfect and imprecise knowledge better than some T1FLS. In future, we intend to learn and fine tune the parameters of the IT2FLS using Gaussian membership function with uncertain mean and train the IT2FLS using hybridized approach by combining neural networks and particle swarm optimization.

\section{REFERENCES}

[1] M. E. Dien, A. A. Youssif, A. Z. Ghalwash "Energy Efficient and QoS Aware Framework for Video Transmission over Wireless Sensor Networks". Wireless Sensor Network, 2016, vol. 8, pp 25-36.

[2] R. Sepúlveda, O. Ross, J. Quĩ nones-Rivera, and E. Quiroz "WLAN Cell Handoff Latency Abatement Using an FPGA Fuzzy Logic Algorithm Implementation. Hindawi Publishing Corporation Advances in Fuzzy Systems. Vol, 2012, Article ID 219602, 1-10 s doi:10.1155/2012/219602

[3] S. Kumar, K. Kumar and K. Pandey "A Comparative Study of Call Admission Control in Mobile Multimedia Networks using Soft Computing. International Journal of Computer Applications (0975 8887) Vol. 107 Issue 16, pp 1-7, 2014.

[4] P. Metre, K. Radhika, Gowrishankar "Survey of Soft Computing Techniques for Joint Radio Resource Management”, 978-1-4673-1520, IEEE 2012.

[5] P. Payaswini, D.H. Manjaiah "Challenges and issues in 4G - Networks Mobility Management". International Journal of Computer Trends and Technology (IJCTT) - volume4 Issue5-May 2013, 1247-1251, 2013.

[6] A. A. Atayero and M. K. Luka 'Applications of Soft Computing in Mobile and Wireless Communications". International Journal of Computer Applications (0975 - 8887), vol. 45 No. 22, pp 48-55, 2012.

[7] I. F. Akyildiz, D. M. Gutierrez-Estevez, E. C. Reyes "The evolution to 4G cellular systems". LTE Advanced Physical Communication, vol. 3 pp 217-244, 2010.

[8] M.ahamed. Call Admission Control in Wireless Network: A Comprehensive Survey. volume 7, no. 1, IEEE communication, 2005.

[8] A. Shukla, Super-Fast 4G Wireless Service Launching in South Korea. Asia-Pacific Buisness and Technology Report, 2011.

[9] G. Mahesh, S. Yeshwanth, U. V. Manikantan "Survey on Soft Computing based Call Admission Control in Wireless Networks". International Journal of Computer Science and Information Technologies, Vol. 5 No. 3, pp 3176 - 3180, 2014.

[10] A. M. Miyim, M. Ismail, R. Nordin and M. T. Ismail "Regressive Prediction Approach to Vertical Handover in Fourth Generation Wireless Networks". J. ICT Res. Appl., vol. 8, No. 1, pp 31-48, 2014.

[11] L. A. Zadeh "Fuzzy Sets". Information and Control, vol. 8, pp 338-353, 1965.

[12] O. Castillo, P. Melin "Type-2fuzzylogic: theory and application". Studfuzz, vol. 223, pp. 29-43, 2008.

[13] E. H. Mamdani and S. Assilian "An experiment in linguistic synthesis with a fuzzy logic controller". International Journal of Man-Machine Studies, vol. 7, no.1, pp. 1-13, 1975.

14] M. V. Ramkumar, A. D. Mihovska, N. R. Prasad and R. Prasad "Fuzzy-Logic Based Call Admission Control for A Heterogeneous Radio Environment". International Jornal of Research in Computer Science, vol. 3, Issue 4, 2016.

[15] M. P. Selvi and S. Sendhilnathan "Fuzzy Based Mobility Management in 4G Wireless Networks". Brazilian Archives of Biology and Technology. vol. 59 no. spe2, 2016, http://dx.doi.org/10.1590/1678-4324-2016161047.

[16] G. U. Mali "Fuzzy Based Vertical Handoff Decision Controller for Future Networks". International Journal of Advanced Engineering, Management and Science (IJAEMS) vol. 3, no.1, 111-119, Jan2017.

[17] R. Abbasi, A. Bidgoli and M. Abbasi, "A New Fuzzy Algorithm For Improving Quality of Service In Real Time Wireless Sensor Networks". International Journal Of Advanced Smart Sensor Network Systems ( IJASSN ), vol. 2, no. 2, pp 1-14, 2012. 
[18] A. Dogman, R. Saatchi, and S. Al-Khayatt, "Quality of Service Evaluation using a Combination of Fuzzy C-Means and Regression Model”. World Academy of Science, Engineering and Technology vol. 6, pp. 562-571, 2012.

[19] J. Ye, X. Shen, and J. Mark, "Call admission control in wideband CDMA cellular networks by using fuzzy logic”. IEEE Trans. Mobile Comput., vol. 4, no. 2, pp. 129-141, 2005.

[20] C. Sonmez, O. Incel, S. Isik, M. Donmez and C. Ersoy, "Fuzzy-based congestion control for wireless multimedia sensor networks". Sonmezet al. EURASIP Journal on Wireless Communications and Networking, no. 63, pp 1-17, 2014.

[21] Y. Bazaz1, S. Kumar and S. Anand, "Congestion Control Mechanism using Fuzzy Logic".International Journal of Emerging Trends \& Technology in Computer Science (IJETTCS) vol. 2, no. 2, pp. 313-319, 2013.

[22] H. Hagras "Type-2 flcs: A new generation of fuzzy controllers".IEEE Computational Intelligence Magazine, vol. 2, no. 1, 30-43, 2007.

[23] J. M. Mendel, Uncertain Rule-Based Fuzzy Logic Systems: Introduction and New Directions, Prentice-Hall, Upper Saddle River, NJ, 2001.

[24] L. A. Zadeh, "The concept of a linguistic variable and its application to approximate reasoning-1," Inf. Sci., vol. 8, pp. 199-249, 1975.

[25] N. N. Karnik and J. M. Mendel, "Centroid of a type-2 fuzzy set," Information Sciences, vol. 132, pp. 195-220, 2001.

[26] D. R.Wu and W. W. Tan "Computationally efficient type-reduction strategies for a type-2 fuzzy logic controller”, in FUZZ-IEEE, Reno, USA pp. 353-358, , May, 2005.

[27] Wu, Dongrui (2005), Design and analysis of Type-2 Fuzzy Logic Systems. A Master's Thesis, Department Of Electrical Aad Computer Engineering, National University of Singapore 2005

[28] J. M. Mendel, "Fuzzy sets for words: a new beginning," in Proceedings of the 12th IEEE International conference on Fuzzy Systems, pp. 37-42, Los Angeles, Calif, USA, May 2003.

[29] D. Wu and J. M. Mendel, "A vector similarity measure for linguistic approximation: interval type-2 and type-1 fuzzy sets," Information Sciences, vol. 178, no. 2, pp. 381-402, 2008.

[30] H.M. Fayek , I.Elamvazuthi N.Perumal , B.Venkatesh (2014). A controller based on OptimalType-2 FuzzyLogic:Systematic design, optimization and real-time implementation. ISA Transactions, vol. 53, pp. 1583-1591, 2014.

[31] Q. Ren, M. Balazinski and Luc Baron "Type-2 TSK Fuzzy Logic System and its Type-1 Counterpart”. International Journal of Computer Applications (0975 - 8887) vol. 20. no.6, pp. 8-14, April 2011.

[32] R. Sarojinee, V. Gupta, M. K. Jha and M. F. Qureshi "Development of Interval Type-2 Fuzzy Logic Controller for Polymer Extruder Melt Temperature Control”. International Journal of Innovative Research in Science, Engineering and Technology, Vol. 4, Issue 2, February 2015, 593-605.

[33] J. Mendel "Type-2 fuzzy sets: Some questions and answers," IEEE Connections, vol. 1, pp. 10-13, Aug. 2003.

[34] Q Liang, N. N. Karnik "Connection Admission Control in ATM Networks Using Survey-Based Type2 Fuzzy Logic Systems'. IEE Transactions on Systems, Man, and Cybernetics-Part C: Applications and Reviews, vol. 30, no. 3., pp. 329-340, August 2000.

[35] S. Shukla, M. Jha, M. F. and Qureshi "An Interval Type-2 Fuzzy Logic Approach for Induction Motors Stator Condition Monitoring”. IJISET - International Journal of Innovative Science, Engineering \& Technology, vol. 1 no. 5, 96-112, July 2014.

[36] M. Khosla, R. K. Sarin and M. Uddin "Design of an Analog CMOS Based Interval Type-2 Fuzzy Logic Controller Chip". International Journal of Artificial Intelligence and Expert Systems, vol. 2, no. 4, 169-186, 2011.

[37] E. A. Jammeh, M. Fleury, C. Wagner, H. Hagras, and M. Ghanbari, "Interval type-2 fuzzy logic congestion control for video streaming

[38] H. Wu and J. M. Mendel "Uncertainty Bounds and Their Use in the Design of Interval Type-2 Fuzzy Logic Systems”. IEEE Transactions on Fuzzy Systems, vol. 10, no. 5, 622-640, 2011.

[39] J. Mendel, H. Hagras and R. John Standard Background Material About Interval Type-2 Fuzzy Logic Systems. "Unpublished".

[40] J. Mendel and R. John, "Type-2 fuzzy sets made simple," IEEE Transactions on Fuzzy Systems, vol. 10, no. 2, pp. 117-127, 2002.

[41] N. N. Karnik, J. M. Mendel and Q. Liang, "Type-2 fuzzy logic systems," IEEE Trans on Fuzzy Systems, vol. 7, pp. 643-658, Dec. 1999. 
[42] J. M. Mendel and F. Liu, "Super-exponential convergence of the Karnik-Mendel algorithms for computing the centroid of an interval type-2 fuzzy set," accepted for publication in IEEE Trans on Fuzzy Systems, 2006.

[43] Hani Hagras, (2009), “General Type-2 Fuzzy Logic Systems to Enable Better Uncertainty Handling for Real World Application". The University of Essex, England, UK.

[44] U. A. Umoh and U. G. Inyang 'A Fuzzy-Neural Intelligent Trading Model for Stock Price Prediction”. IJCSI International Journal of Computer Science Issues, vol. 12, no. 3, pp. 36-44, May 2015.

[45] O. Castillo and P. Melin, Recent Advances in Interval Type-2 Fuzzy Systems vol. 1. USA: Springer, 2012.

[46] Ramkumar, M. and Mandalika, V. (2010). Fuzzy-logic Based Call Admission Control for a Heterogeneous Radio Environment. The 12th International symposium on wireless personal multimedia communication.

Umoh U. A. had received her Doctor of Philosophy $(\mathrm{PhD})$ degree in Soft Computing from University of Port Harcourt, Rivers State, Nigeria in the year 2012, Master's degree in Database Management System from University of Port Harcourt, Rivers State, Nigeria in the year 2006 and Bachelor's degree from University of Uyo, Akwa Ibom State, Nigeria in 2007. She is currently working as a Senior Lecturer, in theUniversity of Uyo in the Department of Computer Science. She has published several articles in her areas in reputable national and international journals and has written some quality books in Computer discipline. Her area of interest include; Soft

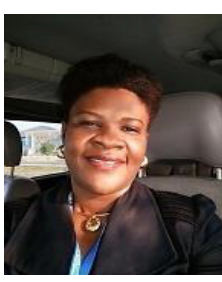
Computing (Fuzzy System, Neural network, Hybrid models), Database System, Data Communications, etc. She is a member of Nigerian Computer Society (NCS), Member, Computer Professionals Registration Council of Nigeria (CPN), member, Nigerian Women in Information Technology (NWIT), member, Organization for Women in Science in Developing World (OWSD), member, Universal Association of Computer and Electronics Engineers (UACEE), member, Soft Computing Research Group (SCRS), member, Internet Society (ISOC), etc.

Daniel Asuquo holds a PhD, M.Sc., and B.Sc. in Computer Science from the University of Port Harcourt, University of Ibadan, and University of Calabar, Nigeria, respectively. He is a Lecturer in the department of Computer Science, University of Uyo, Nigeria with research interest in intelligent approach to wireless networks design and optimization, mobile and web computing. He is a registered member of Nigeria Computer Society and Computer Professionals (Registration Council of Nigeria).

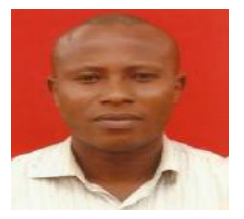

Imo Eyoh received her B.Sc and M.Sc degrees in Computer Science from the University of Uyo and Ibadan respectively, all in Nigeria. She is currently a Ph.D student in the Automated Scheduling, Optimisation and Planning (ASAP) and Laboratory for Uncertainty in Data and Decision Making (LUCID) research groups, University of Nottingham, UK. Her research interest is in uncertainty modeling using both classical and intuitionistic type-2 fuzzy logic systems. 